\title{
Posterior Cingulate Cortex
}

National Cancer Institute

\section{Source}

National Cancer Institute. Posterior Cingulate Cortex. NCI Thesaurus. Code C154778.

The caudal region of the cingulate cortex, located within the medial part of the inferior parietal lobule, that is thought to function as an interface between emotion and cognition. 